\title{
A tectonic interpretation of the Marmara Sea, NW Turkey from geophysical data
}

\author{
Abdullah Ates ${ }^{1}$, Funda Bilim² ${ }^{2}$ Aydin Buyuksarac ${ }^{2}$, and Özcan Bektas ${ }^{1}$ \\ ${ }^{1}$ Ankara University, Faculty of Engineering, Department of Geophysical Engineering, 06100, Besevler, Ankara, Turkey \\ ${ }^{2}$ Cumhuriyet University, Faculty of Engineering, Department of Geophysical Engineering, 58140, Sivas, Turkey \\ (Received October 30, 2006; Revised May 15, 2007; Accepted December 18, 2007; Online published March 3, 2008)
}

\begin{abstract}
Recent scientific investigations have revealed the deep structure and fault mechanisms in the Marmara Sea and surroundings. However, magnetic and gravity anomalies display interesting features which were not resolved in detail. In this paper, simple two-dimensional magnetic and gravity models are constructed utilizing parameters such as the density contrast and susceptibilities obtained from a borehole, seismic sections and field susceptibility measurements, respectively. The gravity model shows the existence of horst-like structures, as suggested previously. The top of the magnetic bodies in the Marmara Sea is close to the sea bottom. In general, these magnetic bodies are fault-related. The gravity model complies with the seismic base map, which was constructed previously. The magnetic anomalies of anomalous regions of the Cinarcik and Western Basins demonstrate slight anticlockwise block rotations, while large anticlockwise block rotation is observed in the eastern extremity of the Marmara Sea. Geophysical data and modeling results suggest that the origin and evaluation of the Marmara Sea began with the possibility of emplacement of horst-like structures in the Central Ridge during the Palaeozoic or earlier followed by block rotations and intrusion of the magnetic material into the upper crust with sediment deposition and faulting. It can also be suggested that the horst-like structures in the central Marmara act to diffuse the propagation of the Northern Boundary Fault (NBF). This aspect is correlated with the focal mechanisms of the major earthquakes.
\end{abstract}

Key words: Marmara Sea, geophysical data, tectonic interpretation, block rotations.

\section{Introduction}

It is generally accepted that the Anatolian crust is extending in response to forces exerted on it by subduction of the African plate beneath its southern margin. Southwestward movement of the Anatolian plate in this area is also caused by this subduction (Meijer and Wortel, 1997).

Barka and Kadinsky-Cade (1998), Imren et al. (2001) and Demirbag et al. (2003) attempted to resolve the deep structure of the Marmara Sea by seismological and seismic data. These researchers named the fault at the centre of the Marmara Sea as the main Marmara fault and studied this fault by using deep towed seismic data. However, the penetration of their data was not enough to obtain deep structural information. A simplified tectonic map is given in Fig. 1. The north of the Marmara Sea, which is called "the Istanbul Zone", is constituted of rigid block. Ates $e t$ al. (2003) studied the deep structure of the Marmara region utilizing aeromagnetic, seismic and gravity data. They proposed a basement map for the Tertiary base and a fault map constructed by the seismic, aeromagnetic and surface observations. It was also suggested that a rigid block situated at the dorsal zone acting as a restraining bent a key factor determining earthquakes in the Marmara Sea and surroundings. Bariş et al. (2005) studied the three-dimensional

Copyright (c) The Society of Geomagnetism and Earth, Planetary and Space Sciences (SGEPSS); The Seismological Society of Japan; The Volcanological Society of Japan; The Geodetic Society of Japan; The Japanese Society for Planetary Sciences; TERRAPUB. structure of $V_{p}, V_{s}$ and $V_{p} / V_{s}$ in the upper crust of the Marmara region NW Turkey. Their seismic findings were in line with the gravity and magnetic anomaly profiles previously described by Ates et al. (2003). Aktar et al. (2004) found high $b$-values at asperity, indicating that the crustal material had been severely crushed due to high slip during the main shock rupture of the Izmit earthquake on 17 August 1999. High $b$-values also indicate reactivation of highly fractured zones due to this major earthquake. Aftershocks are not directly related to the main shock, and there is a possibility of trapped fluids in small fractures. Muller and Aydin (2004) predicted possibility of future ruptures in the Sea of Marmara suggesting potential ruptures along the Yalova and Armutlu faults shown in Fig. 1. They also suggested a potential rupture line to the west of the 1999 Izmit earthquake along the E-W direction. Their suggestions were based on regional stress field orientation. Sato et al. (2004) studied the microearthquake seismicity and focal mechanisms of the Sea of Marmara using ocean bottom seismometers (OBSs). It was observed that the microseismicity mainly occurred along a major fault described as the Main Marmara Fault (MMF). Focal depth distribution was shallower than $20 \mathrm{~km}$ along the western part of the MMF and shallower than $15 \mathrm{~km}$ along its eastern part. Öncel and Wilson (2006) recently evaluated the earthquake potential along the North Anatolian Fault (NAF) Zone in the Marmara Sea using a comparison of GPS strain and tectonic parameters. They also suggested that the NBF serves as 


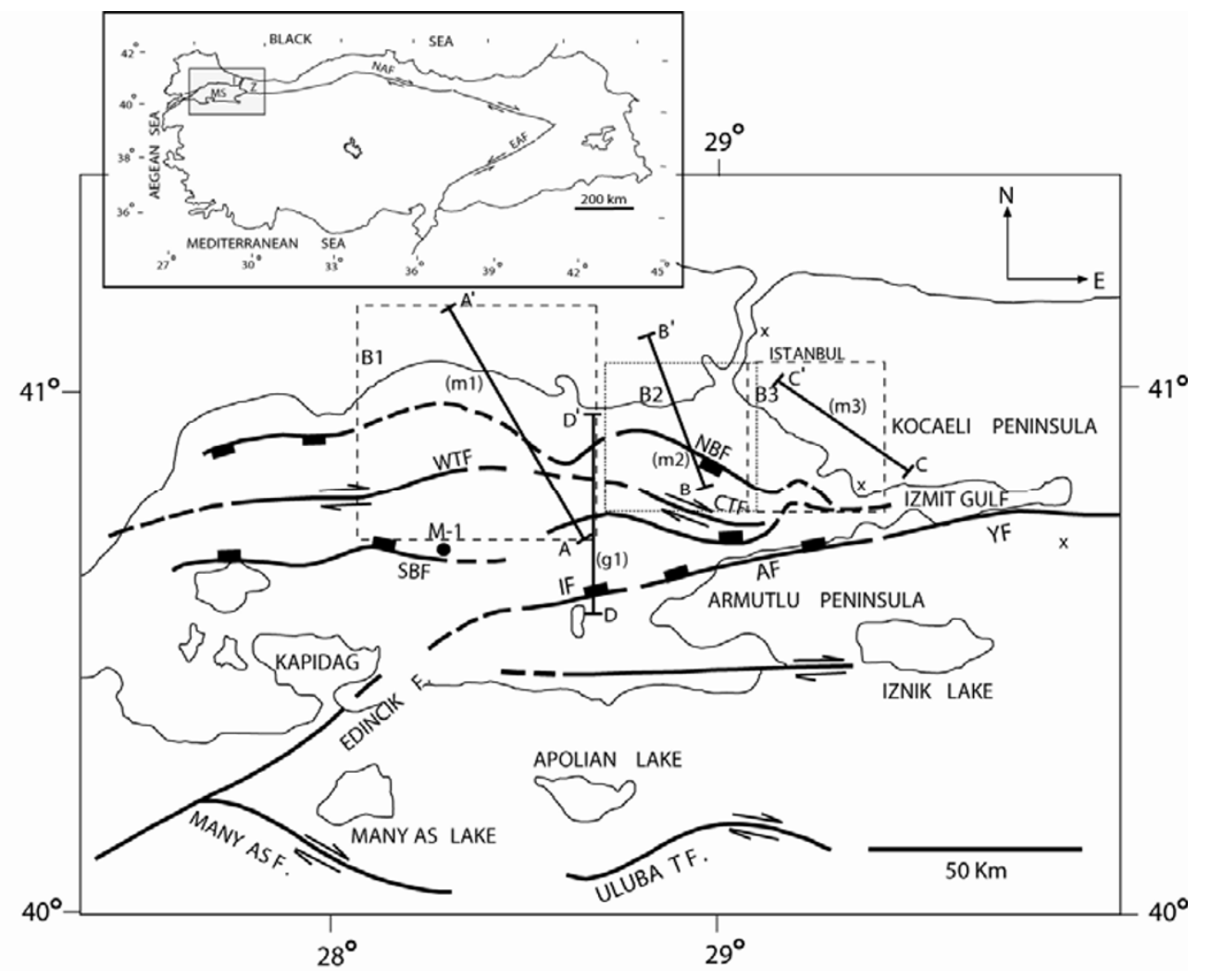

Fig. 1. Location and tectonic maps of the study region. Doted square in the location map shows the study area, MS and IZ are the Marmara Sea and Istanbul Zone, respectively. Main tectonic features of the Sea area of the Marmara region are modified from Ates et al. (2003). Solid lines m1, m2 and $\mathrm{m} 3$ are aeromagnetic anomaly profiles. g1 is the marine Bouguer anomaly profile. WTF: Western Transform Fault, CTF: Cinarcik Transform Fault, NBF: Northern Boundary Normal Fault, SBF: Southern Boundary Fault, IF: Imrali Fault, YF: Yalova Fault, AF: Armutlu Fault, M-1: Location of Marmara-1 borehole. X signs show the susceptibility measurements taken regions.

an impediment to transfer the strain from east to west due to a bend situated there. In this paper, we provide simple two-dimensional magnetic and gravity models of the deep structure of the Marmara Sea using density and susceptibility data as parameters. The density data were obtained from seismic velocities and borehole sonic logs (Ates et $a l ., 2003$ ). The two-dimensional models provide further detailed information on the deep structure of the Marmara Sea. Magnetic models appear to be fault related and intercalated with sediments. The gravity model shows restraining bents (horsts) in the centre of the Marmara Sea along the NBF, as also depicted by Öncel and Wilson (2006). An advanced method, which was developed by Bilim and Ates (2007) to determine the remanent magnetization effect on rotations, was applied to the parts of the North Marmara Sea anomaly; the results suggest anticlockwise rotations of the Anatolian Block against the Eurasian Block in the north, while the western and central parts of the Marmara Sea show slight anticlockwise rotation, and the easternmost section shows large anticlockwise rotation.

Focal mechanisms of major earthquakes adopted from Ambraseys and Jackson (2000) can not easily be correlated with the Central Ridge horst defined earlier as the restraining bent.

\section{Geodynamic Setting}

The geodynamic setting of the Marmara region is characterized by the NAF Zone. The right lateral movement of the NAF was initiated in the eastern Anatolia during the Late Miocene and propagated westward reaching the Marmara Sea region during Pliocene (Sengor, 1979). The NAF runs along the Intra-Pontide Suture zone and forms with the Tethyan ocean closure. The NAF splits into several branches in and around the Marmara Sea region because of complexity of the crustal structures.

In the region, there are high-amplitude magnetic anomalies with complex shapes (Ates et al., 1999). One of them has a striking shape with its EW elongation at the north of the Marmara Sea (Ates et al., 2003).

\section{Magnetic, Gravity and Seismic Data}

Aeromagnetic anomalies of the Marmara Sea was lowpass filtered using the cut-off frequency of $0.16 \mathrm{~km}^{-1}$. The low-pass filtered aeromagnetic anomaly map is given in Fig. 2. Low-pass filtering suppresses near surface smallsized magnetic bodies and enhances deeper magnetized bodies. The Northern Marmara Sea displays E-W elongated magnetic anomaly with a length of more than $150 \mathrm{~km}$ extending along the E-W direction. This interesting anomaly separates into three regions (blocks shown in Fig. 1: B1, B2 and B3) based on the shapes of the anomalies.

Magnetic data described by Ates et al. (2003) were restricted to the sea area of the Marmara region, and profiles were taken along the $\mathrm{m} 1, \mathrm{~m} 2$ and $\mathrm{m} 3$ directions. Profile $\mathrm{g} 1$ corresponds to the marine Bouguer anomaly profiles of III of Ates et al. (2003). Locations of profiles $\mathrm{m} 1\left(\mathrm{AA}^{\prime}\right)$ and 


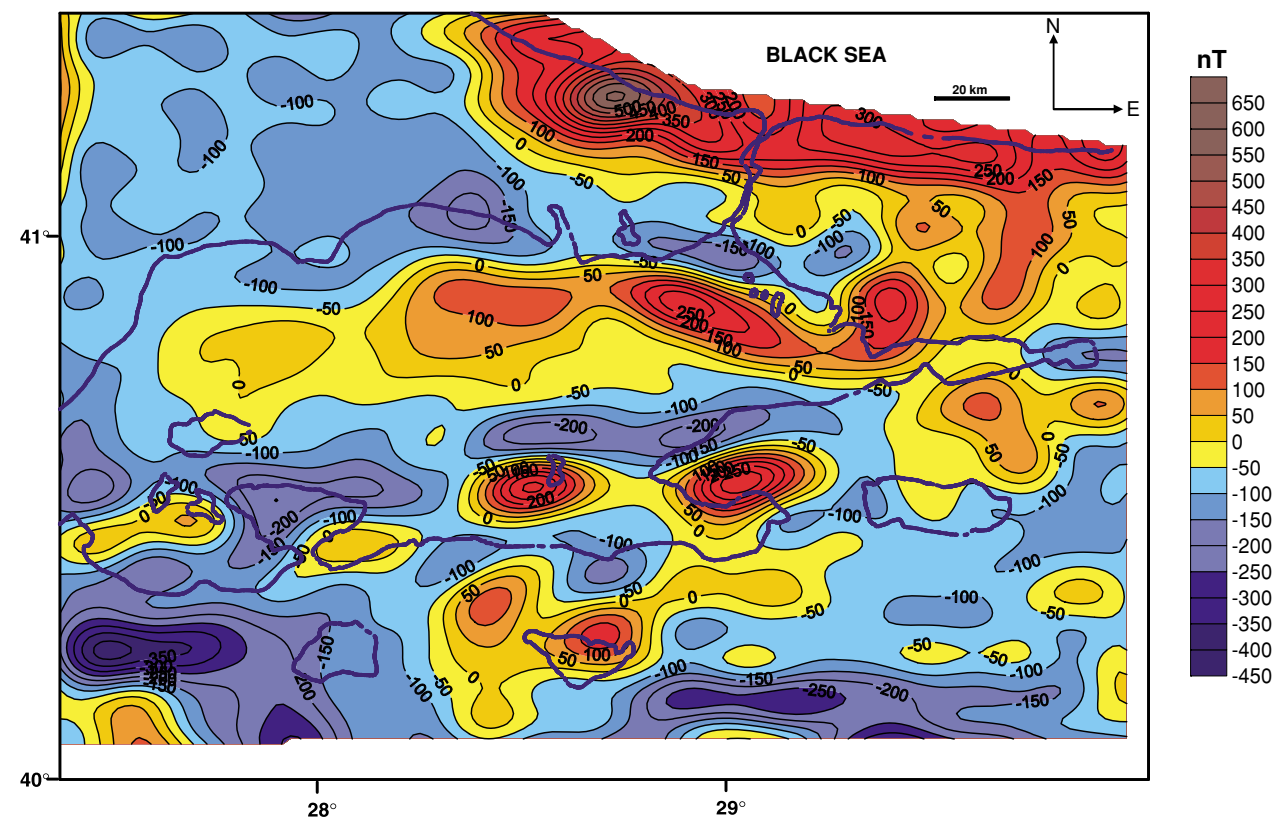

Fig. 2. Low-pass filtered aeromagnetic anomalies of the region shown in Fig. 1. Contour interval=50 nT.

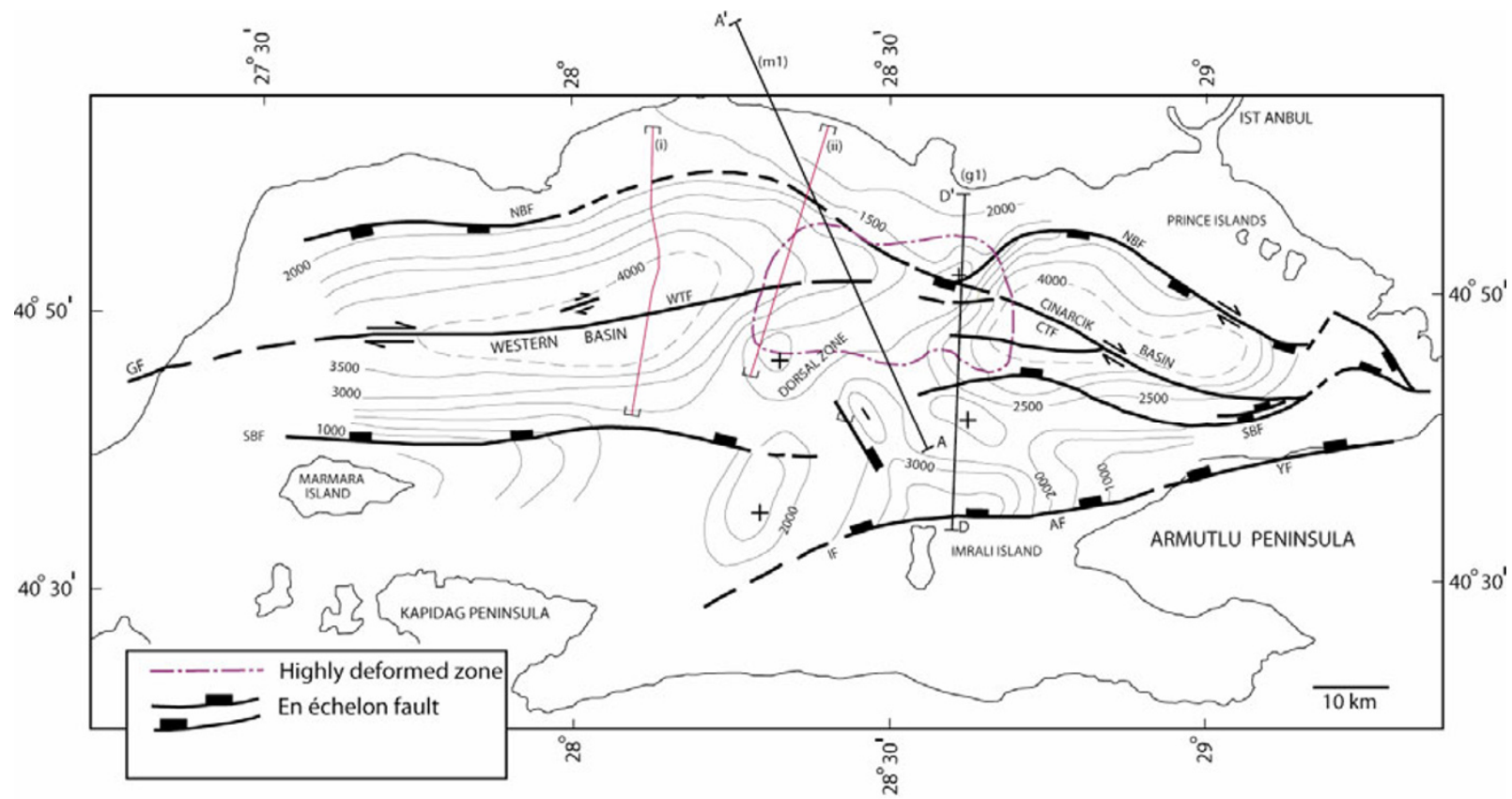

Fig. 3. Fault map of the Marmara Sea simplified from Ates et al. (2003). Contours are two-way travel time in milliseconds. (i) and (ii) are the seismic lines hatched from Ates et al. (2003), $\mathrm{m} 1$ is the magnetic profile along the AA' direction, g1 is the gravity anomaly profile along the DD' direction. GF: Ganos Fault, WTF: Western Transform Fault, CTF: Cinarcik Transform Fault, NBF: Northern Boundary Fault, SBF: Southern Boundary Fault, IF: Imrali Fault.

g1 (DD') are also shown on a fault map that was previously constructed by Ates et al. (2003) (Fig. 3).

Two seismic profiles were taken from Ates et al. (2003) in order to construct a magnetic model in the western part of the Marmara Sea (profile $\mathrm{m} 1$ ). Since the magnetic anomalies are fault related, spaces between the faults in the seismic sections are annotated. These annotated seismic sections are shown in Figs. 4 and 5.

\section{Density and Susceptibility Data}

Velocity information was obtained from a sonic log taken in the Marmara-1 (M-1) borehole. Velocities in this log are 4600 and $3050 \mathrm{~m} \mathrm{~s}^{-1}$ for the Mesozoic and Miocene formations, respectively. The base of the Miocene or top of the Mesozoic formations is $1900 \mathrm{~m} \mathrm{~s}^{-1}$ TWT below sea level (Ates et al., 2003). An average velocity of $3825 \mathrm{~m} \mathrm{~s}^{-1}$ was obtained from this borehole. The depth below $4 \mathrm{~s}$ can be considered to be the basement. Thus, the interval velocities obtained from seismic sections can be as- 


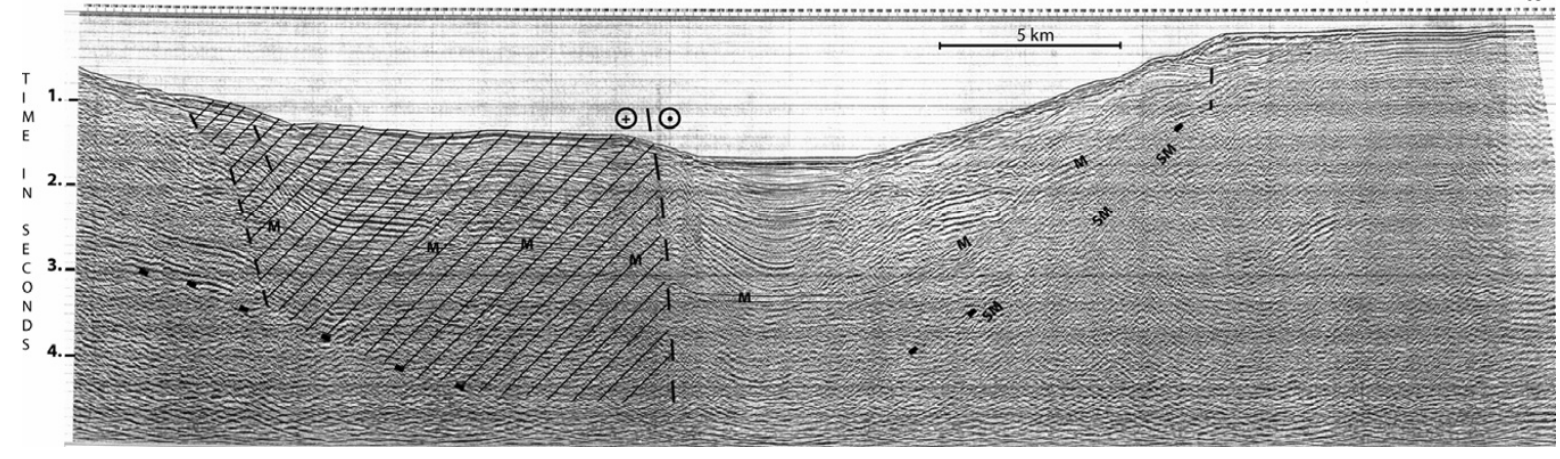

Fig. 4. Seismic section (i) shown in Fig. 3. Hatched region is considered to be magnetized. Vertical axis represents TWTT in seconds.

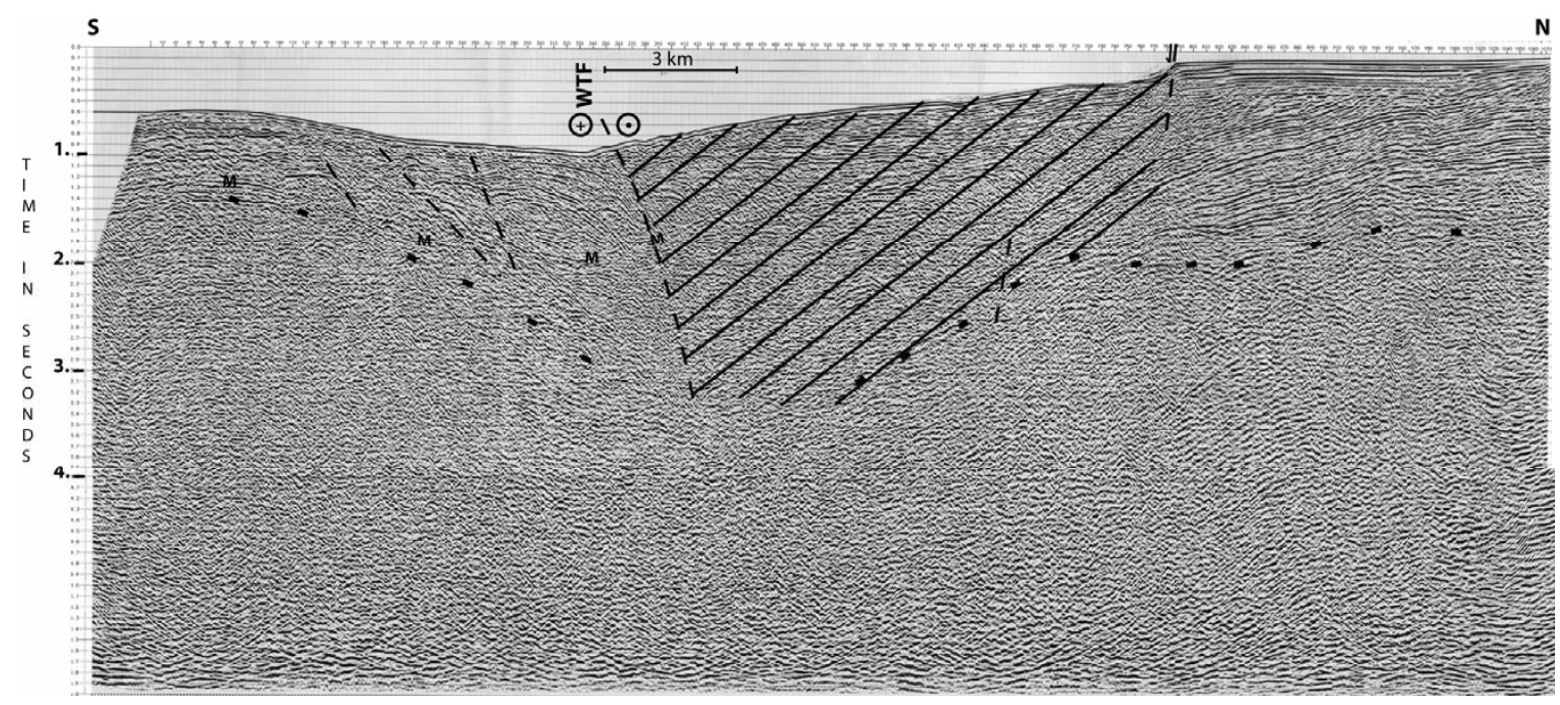

Fig. 5. Seismic section (ii) shown in Fig. 3. Hatched region is considered to be magnetized. Vertical axis represents TWTT in seconds.

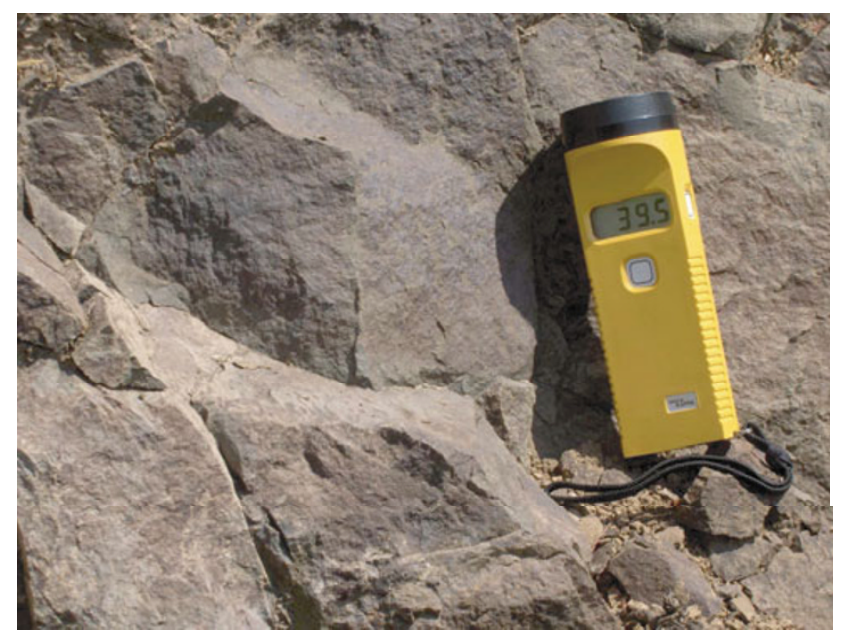

Fig. 6. A photograph showing the magnetized outcrops around the Camiduzu region.

signed to approximately to $6000 \mathrm{~m} \mathrm{~s}^{-1}$ for the basement. We used the density-velocity relationship of Ludwig et al. (1970) to convert approximate RMS velocity in Tertiary basin and interval velocity of the basement. Velocities of 3825 and $6000 \mathrm{~m} \mathrm{~s}^{-1}$ correspond to densities of 2.3 and
$2.7 \mathrm{~g} / \mathrm{cm}^{3}$ (Ludwig et al., 1970). Thus, a density contrast of $-0.4 \mathrm{~g} / \mathrm{cm}^{3}$ can be obtained for the basin with respect to the basement.

Susceptibility measurements were taken from the field using a SCINTREX kappameter KT-6. The measurements were concentrated outcrops of the anomalous regions. For this reason, field measurements were taken over the three regions denoted by $\mathrm{X}$ signs in Fig. 1. These locations are known as the Cavusbasi $\left(41^{\circ} 5.5^{\prime} \mathrm{N}, 29^{\circ} 9.5^{\prime} \mathrm{E}\right)$ and Balcik $\left(40^{\circ} 53^{\prime} \mathrm{N}, 29^{\circ} 24^{\prime} \mathrm{E}\right)$ granitoids and the Camiduzu region $\left(40^{\circ} 39.5^{\prime} \mathrm{N}, 29^{\circ} 57.5^{\prime} \mathrm{E}\right)$. The maximum susceptibility of $0.00315 \mathrm{cgs}$ was measured from the Camiduzu region. Magnetized outcrops are shown in a photograph (Fig. 6).

\section{Magnetic and Gravity Modeling}

Here, we present simple two-dimensional models of magnetic and gravity anomaly profiles of the Marmara Sea using the density data obtained from the seismic velocities and the susceptibility data obtained from the field.

Magnetic profile m1 (Fig. 7(a)) passes along the widest part of the anomaly of the Marmara Sea. The top of the magnetic body is located at the sea bottom. The bottom of the body extends down to the Curie point depth, estimated to be $14.5 \mathrm{~km}$ from surface (Ates et al., 2003). Magnetic profile $\mathrm{m} 2$ (Fig. 7(b)) passes along the sharp and narrow part 

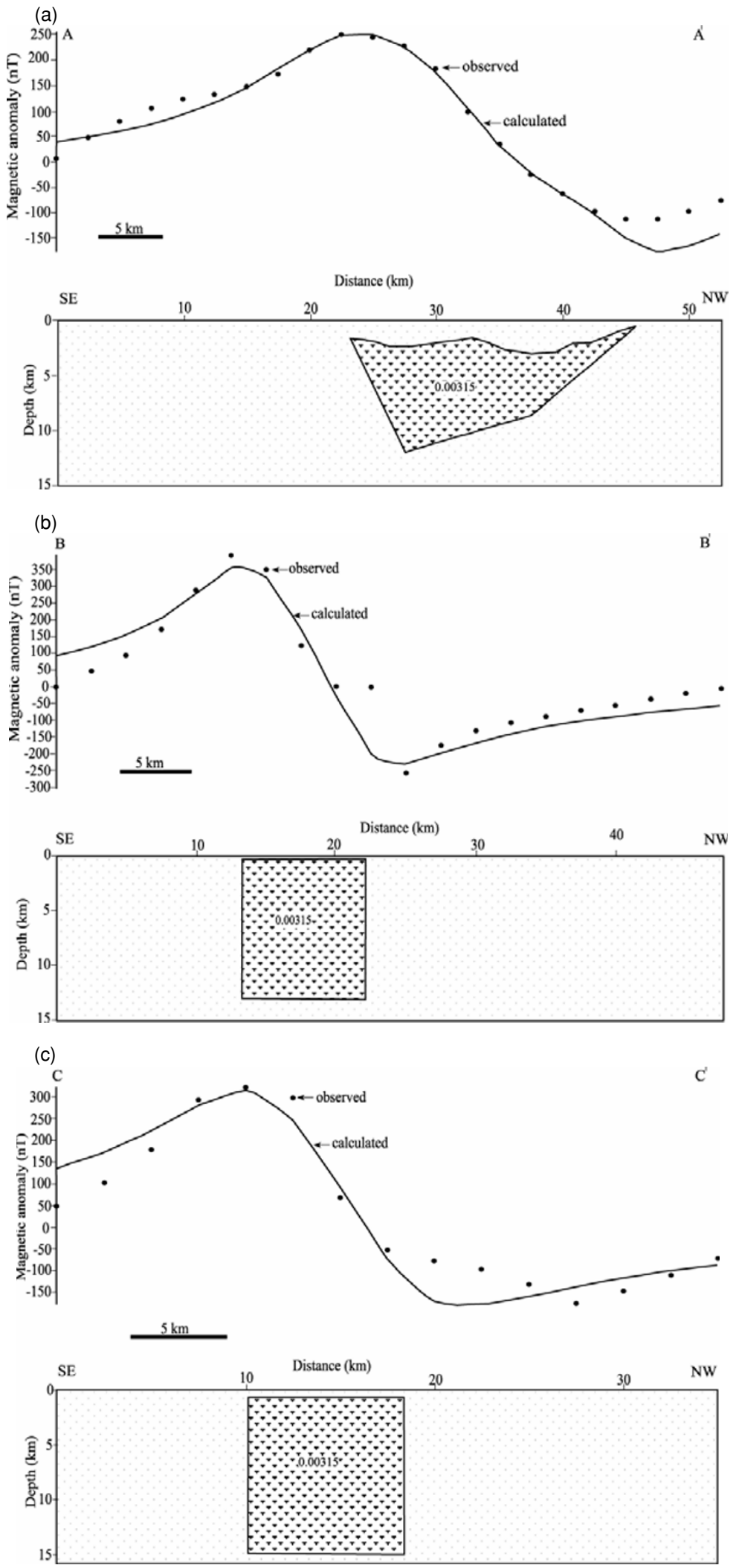

Fig. 7. (a, b, c) Magnetic models constructed along profiles $\mathrm{m} 1, \mathrm{~m} 2$ and $\mathrm{m} 3$, respectively. The susceptibility of the magnetized bodies is $0.00315 \mathrm{cgs}$ (SI). (d) Gravity model constructed along profile g1. Densities of the basement and sedimentary units are shown. IF: Imrali Fault, NBF: Northern Boundary Fault.

of the anomaly and, therefore, the causative body appears to be shallow. A dyke-shaped body with its top at the sea bottom was used to provide the best fit with the calculated and observed anomaly profiles. Magnetic profile m3 (Fig. 7(c)) is located at the eastern edge of the Marmara Sea where the magnetic body tends to turn north towards Black Sea. A dyke-shaped body with its top at the sea bottom (Fig. 7(c)) was used to provide the best fit with the calculated and ob- 


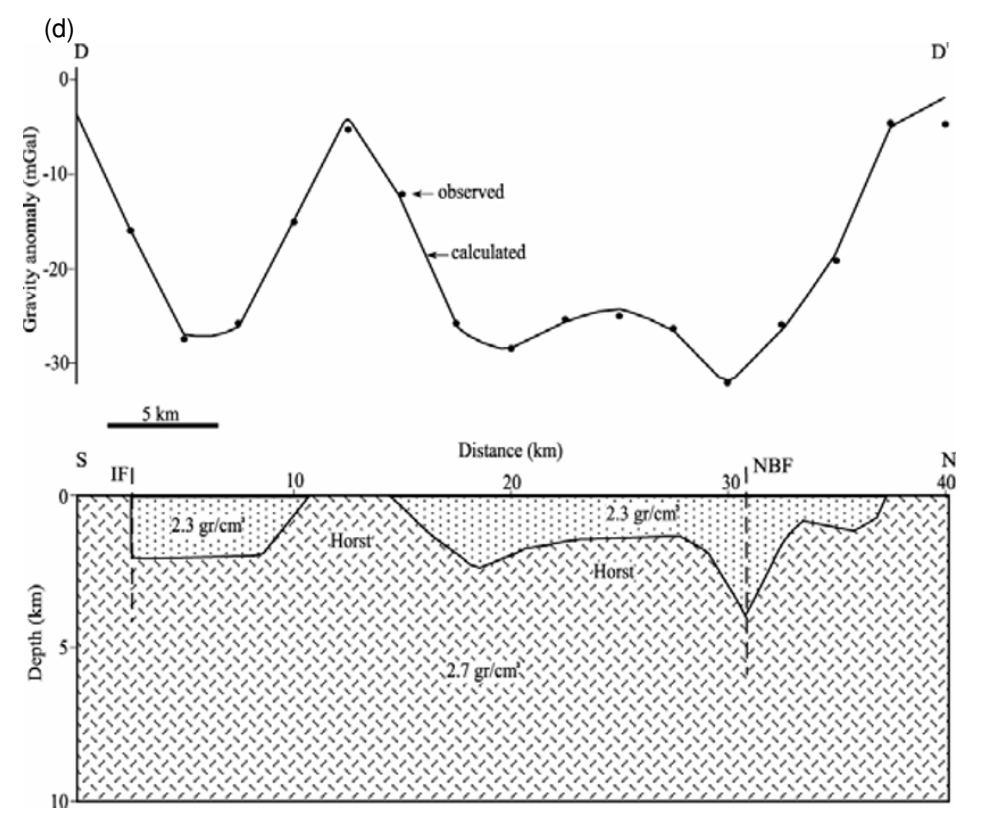

Fig. 7. (continued).

served anomaly profiles. In the magnetic models of profiles $\mathrm{m} 1$ and $\mathrm{m} 2$, the bottom of the bodies was extended down to the Curie point depth of $14.5 \mathrm{~km}$ estimated from spectral analysis (Ates et al., 2003), and the width of the bodies was kept as wide as inferred from the seismic sections (Figs. 4 and 5). Magnetic bodies associated with faults were shown by Tuncer et al. (1991) and Ates et al. (2003).

Gravity model along profile g1 is constructed using sediment thicknesses obtained from seismic profiles. The forementioned density contrast of $-0.4 \mathrm{~g} / \mathrm{cm}^{3}$ was used between the basement and the sedimentary units (Fig. 7(d)).

\section{Block Rotations}

The dipolar source body in northern hemisphere exhibits magnetic anomaly, with a positive peak in the south and a smaller negative peak in the north. If there is a remanent magnetization in the body, the orientation of magnetic anomaly may be different than this orientation. Such distortions can be observed from low-pass filtered aeromagnetic anomalies (Fig. 2). Shape analysis suggests that almost all of the anomalies have a total magnetization direction differing from the induced one. Anomalies with similar characteristics have been reported from the Italian region by Fedi et al. (1991, 1996). These authors suggested dominant effects from remanent magnetization and that the regions investigated had experienced rotations in different directions.

Bilim and Ates (2004) suggested an improved method to determine the magnetization direction from pseudogravity and gravity anomalies of their work (Bilim and Ates, 1999). For the latter, they used Meyer's (1965) correlation coefficient equation $(r)$ to enhance their previous method. Recently, Bilim and Ates (2007) estimated the magnetization direction using only magnetic anomalies. Their method was similar to the Roest and Pilkington (1993) algorithm in which the analytic signal was correlated with the horizontal gradient anomalies. Bilim and Ates (2007) used Meyer's (1965) correlation coefficient equation $(r)$ to correlate the analytic signal and horizontal gradient anomalies. Magnetic anomalies shown at the northern Marmara Sea were divided into three parts from west to east, as shown in Fig. 1. The method described by Bilim and Ates (2007) to estimate the direction of body magnetization was applied to magnetic anomalies of the three regions shown in Figs. 8(a), 9(a) and 10(a). Correlation graphics of these regions are given in Figs. 8(b), 9(b) and 10(b). The estimated declination of the magnetization angles of the three regions from west to east are $-5^{\circ},-6^{\circ}$ and $-68^{\circ}$. This would mean that the two regions in the west (Blocks 1 and 2) rotated slightly in an anticlockwise direction and that the region in the east (Block 3) largely rotated in an anticlockwise direction. The central dorsal zone described by Ates et al. (2003) acted as a restraining bent to prevent the western region from rotation. Block 3 was severely affected by the anticlockwise rotation. Estimated inclinations of the magnetization angles of the three regions west to east are $48^{\circ}, 40^{\circ}$ and $50^{\circ}$. These estimated inclination of magnetizations are slightly low compared to the inclination angle of the present geomagnetic field in the region. This would imply that these regions gained their magnetization when Turkey was at low latitudes.

\section{Discussion and Conclusion}

In the north of the Marmara Sea aeromagnetic anomaly displays an E-W elongation with high intensity and appears to be connected to the Black Sea in the east. This anomaly appears to be caused by wide and shallow magnetized bodies. Using the constraints obtained by seismic analysis, we have modeled aeromagnetic anomaly profiles $\mathrm{m} 1$ and $\mathrm{m} 2$ (Fig. 2). Aeromagnetic anomalies of profile $\mathrm{m} 2$ were modeled by a vertical dyke (Fig. 7(b)). These magnetized dykes are the magnetic material filling inside the fault zones of the northern boundary of normal faults (NBF) (Fig. 1). One more aeromagnetic profile was taken along line $\mathrm{m} 3$, as shown in Fig. 1, to provide further control to the depth of 


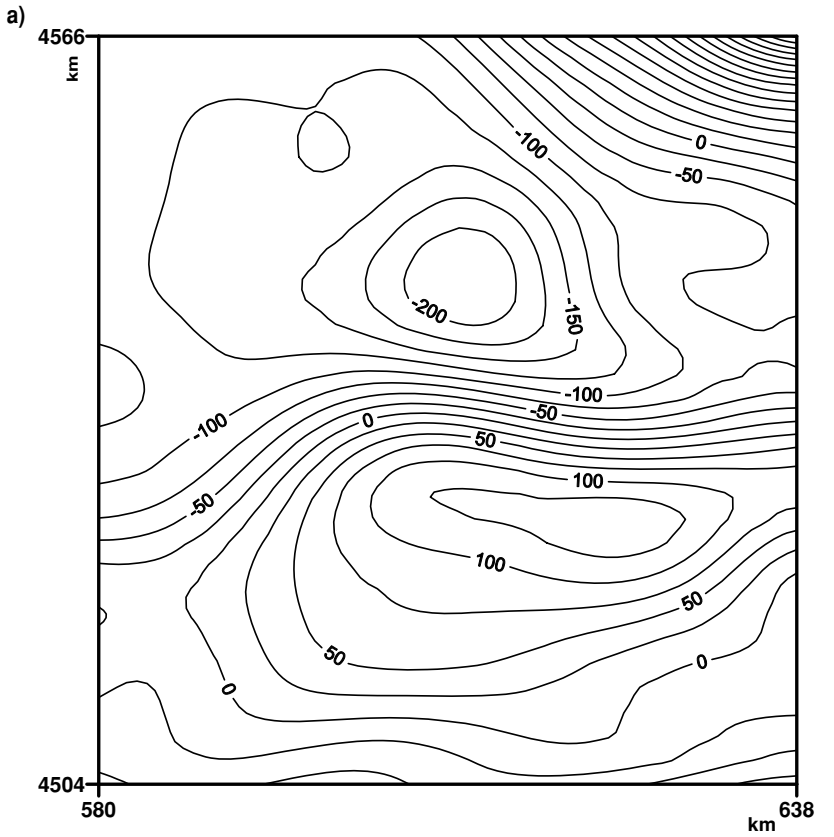

b)

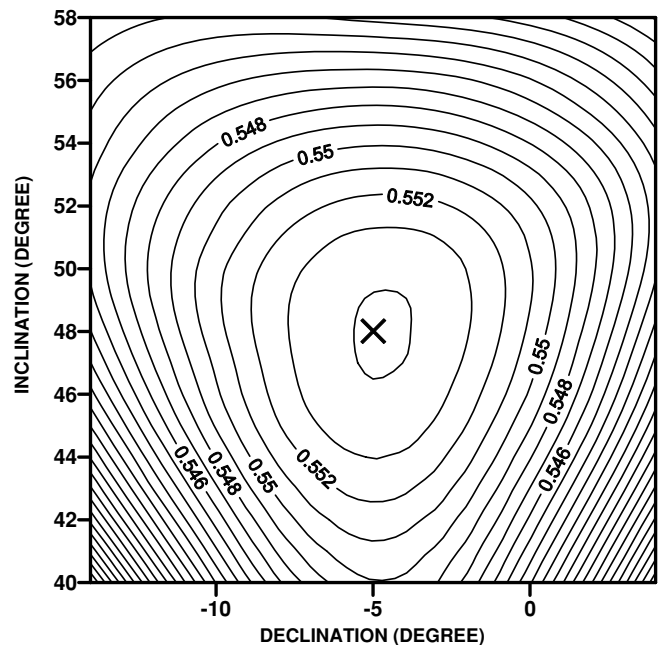

Fig. 8. (a) Aeromagnetic anomalies of region B1 shown in Fig. 2. (b) Contour map of the correlation coefficient $(r)$ for the estimated magnetization angles of declination and inclination. $\mathrm{X}$ denotes the declination and inclination angles of $-5^{\circ}$ and $48^{\circ}$, respectively.

a)

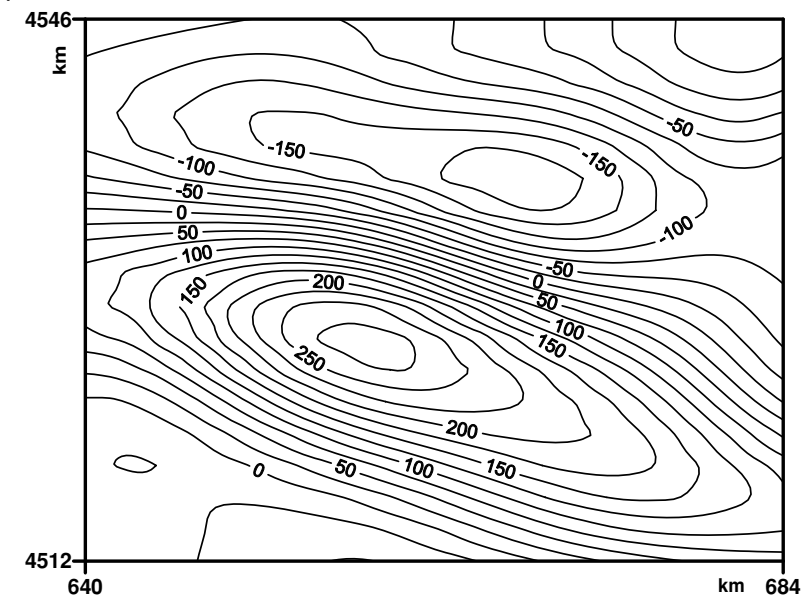

b)

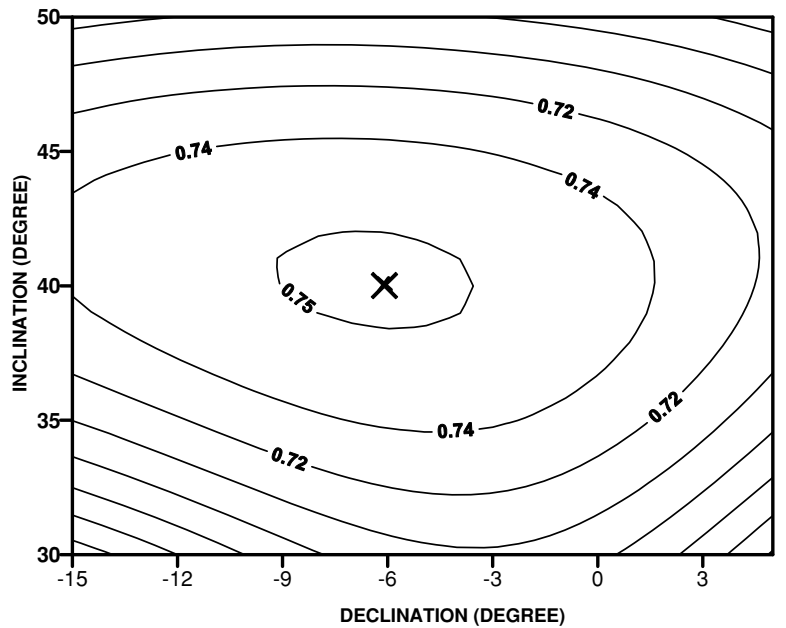

Fig. 9. (a) Aeromagnetic anomalies of region B2 shown in Fig. 3. (b) Contour map of the correlation coefficient $(r)$ for the estimated magnetization angles of declination and inclination. $X$ denotes the declination and inclination angles of $-6^{\circ}$ and $40^{\circ}$, respectively.

magnetized body. A dyke-like model is observed in profile $\mathrm{m} 3$ (Fig. 7(c)). The widths of the dykes were chosen as thick as observed from the seismic sections (Ates et al., 2003). In all cases the susceptibilities of the models were taken as $0.00315 \mathrm{cgs}$ (SI), as measured from the field. The bottom depths of all three models are approximately between 14 and $15 \mathrm{~km}$. This finding is in agreement with the shallow Curie depth of the Sea of Marmara calculated by Ates et al. (2003).

Bouguer anomaly profile 1 passes through the east of the Central Ridge (shown in Fig. 11) described by Ates et al. (2003), which separates the Western and Cinarcik Basins. Two basement high structures can be seen along this profile. These basin highs are delimited with normal faults and can be described as horst-like structures inside the main Marmara Sea normal faults (NBF and SBF). In the Central Ridge horst area (Fig. 11), magnetic anomaly is observed in the north and thus is related to the Northern Boundary Fault (NBF). The horst-like Central Ridge is non-magnetic, and the deep-seated E-W elongated magnetic anomaly becomes weak in terms of amplitude and size in this area. Thus, the emplacement of the Central Ridge horst must be older than the magnetic material. A similar Palaeozoic/Precambrian(?) horst can be seen in the south of England along the Mendip Hills, emplaced into the upper crust (Ates and Kearey, 1993). The model of the gravity anomaly profile g1 (Fig. 7(d)) was constructed with the help of previously interpreted seismic sections (Ates et al., 2003).

The available focal mechanisms of the major earthquakes 
a)
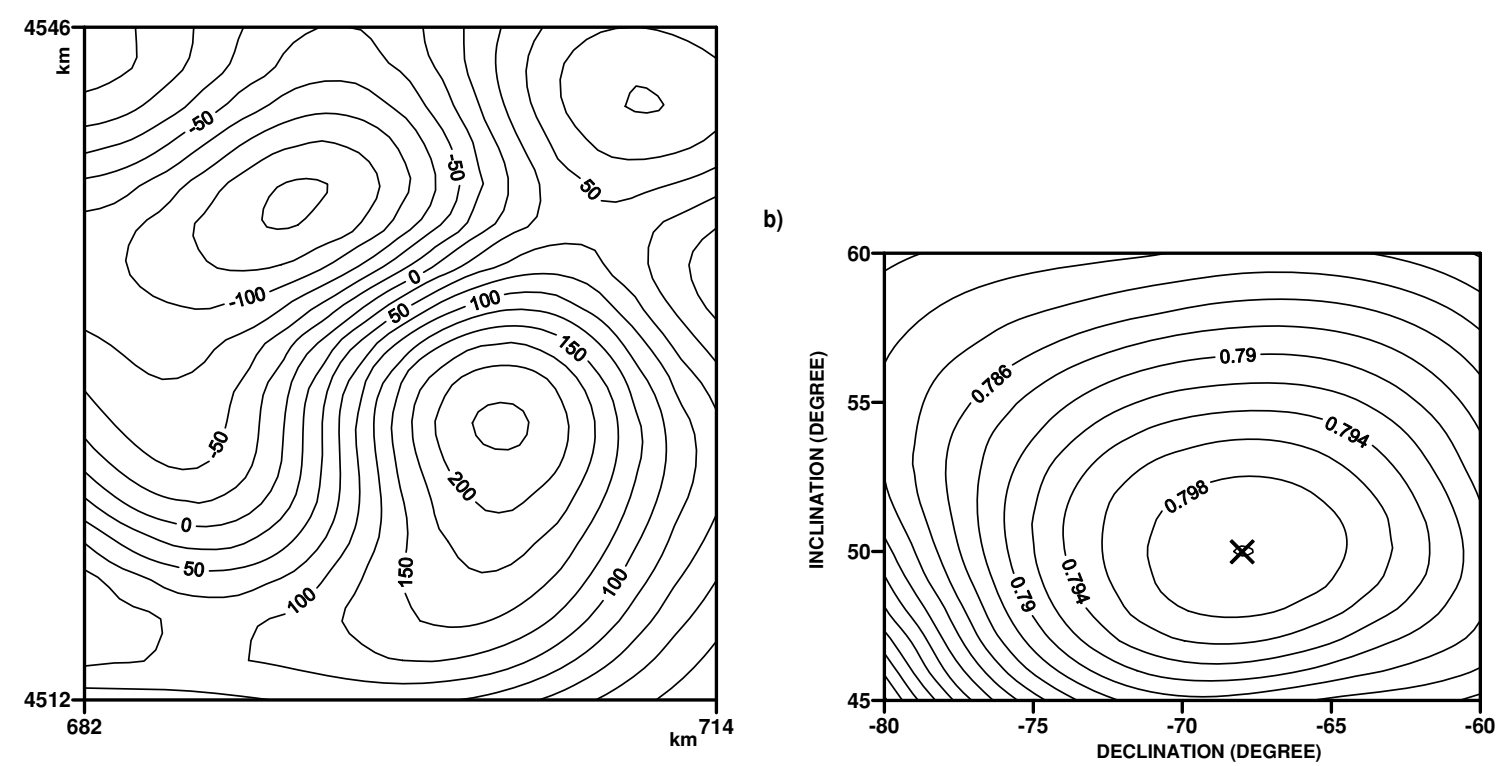

Fig. 10. (a) Aeromagnetic anomalies of region B3 shown in Fig. 3. (b) Contour map of the correlation coefficient $(r)$ for the estimated magnetization angles of declination and inclination. X shows the declination and inclination angles of $-68^{\circ}$ and $50^{\circ}$, respectively.

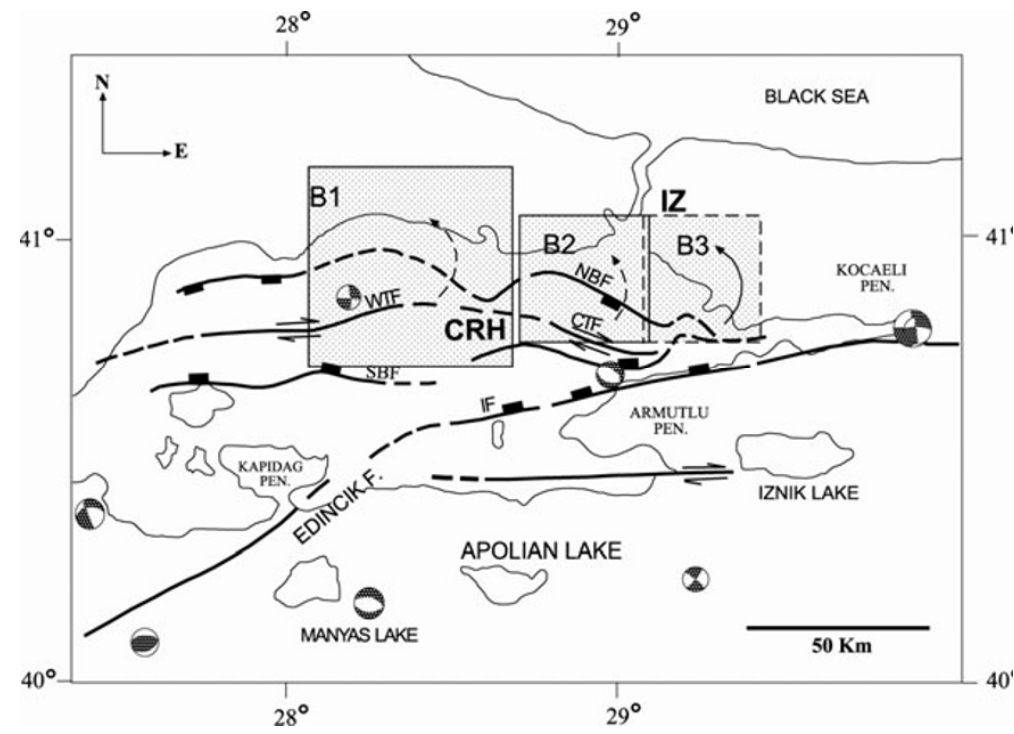

Fig. 11. Block rotations deduced from the magnetic interpretation, IZ: Istanbul Zone, CRH: Central Ridge Horst. Focal mechanisms of large earthquakes are adapted from Ambraseys and Jackson (2000).

obtained from Ambraseys and Jackson (2000) were placed in Fig. 11 to monitor the correlation along the faults and to comprehend the tectonic evolution of the region. The absence of a major earthquake can be observed along the Central Ridge Horst.

Low-pass filtered aeromagnetic anomalies of three selected regions in the central Marmara Sea were analyzed to estimate the direction of remanence utilizing a method developed by Bilim and Ates (2007). Small anticlockwise rotations were estimated in Blocks 1 and 2. Block rotations were obtained at Blocks B1, B2 and B3 along WTF and CTF with different angles. The reason for this is the behavior of the Central Ridge: it acts as a barrier and prevents the rotational movement on the WTF. In the east, Block 3 rotated largely in an anticlockwise direction, and this can be realized by a discontinuity between Blocks 2 and 3 (Fig. 1). This tectonic discontinuity between zones 2 and 3 was also deduced by the interpretation of seismic sections. It was shown by Ates et al. (2003) that the close examination of sections at the Gulf of Izmit reveals an unexpected discontinuity in the orientation of the northern and southern NAFs. Geologically, it appears to be associated with the SW extension of the Princes Islands palaeohigh.

The low degree of inclination of body magnetization is evidence of the northwards drift of the region. The northwards drift of the continents is well documented in the mobilistic principle of Storetvedt (2003). The anticlockwise rotation of Anatolia against the stable Eurasian Plate is presented by GPS measurements (McClusky et al., 2000). The E-W elongation of the aeromagnetic anomaly of the cen- 
tral Marmara Sea is consistent with the mobilistic system of Storetvedt (2003). There is a similar barrier to the east of the study area in land known as the "Almacik Flake" (Saribudak et al., 1990). The estimated inclinations of magnetization are low compared to the inclination angle of the present geomagnetic filed in the region. This would imply that these regions gained their magnetization when Turkey was at low latitudes. The inclination of the magnetization angle of Block 3 is about $13-14^{\circ}$ lower than that of Blocks 1 and 2. It is possible that Block 3 was rotated along the horizontal axis. A similar result was obtained by the palaeomagnetic works of Michel et al. (1995) in the land area to the east of the Marmara Sea.

As a result of this work, the geodynamic evolution of the Marmara region can be proposed: (1) emplacement of the Central Ridge horst during Palaeozoic/Precambrian? (2) block rotations; (3) intrusion of the magnetic material and sediment deposition. The presence of the Central Ridge horst appears to diffuse the propagation of the NBF and SBF towards the west, and this was also suggested by Ates et al. (2003) and Öncel and Wilson (2006). Palaeozoic formations of Istanbul have similarities to the Central Ridge horst. There is a possibility that the Palaeozoic formation of Istanbul was detached from the Central Ridge horst by the dextral strike slip of the North Anatolian Fault. However, this matter needs further investigation to be proved.

Acknowledgments. We thank the Mineral Research and Exploration Company (MTA) of Turkey and Turkiye Petrolleri A. O. (TPAO) for providing potential field data and seismic reflection profiles, respectively. We thank Prof. Naoshi Hirata for his effort during the review process and two anonymous referees for their constructive criticism. The directorate of Scientific Research Projects (BAP) of Ankara University, grant number 2003.07.45.017 and Turkish Scientific and Technical Research Council (TUBITAK), grant number 103Y125 supported this project.

\section{References}

Aktar, M., S. Özalaybey, H. Karabulut, M.-P. Bouin, C. Tapırdamaz, F. Biçmen, A. Yörük, and M. Bouchon, Spatial variation of aftershock activity across the rupture zone of the 17 August 1999 Izmit earthquake, Turkey, Tectonophysics, 391, 325-334, 2004.

Ambraseys, N. N. and J. A. Jackson, Seismicity of the sea of Marmara (Turkey) since 1500, Geophys. J. Int. (Fast-Track paper), 141, F1-F6, 2000.

Ates, A. and P. Kearey, Structure of the Blackdown Pericline, Mendip Hills from gravity and seismic data, J. Geol. Soc. (Lond.), 150, 729-736, 1993.

Ates, A., P. Kearey, and S. Tufan, New gravity and magnetic maps of Turkey, Geophys. J. Int. (Research Note), 136, 499-502, 1999.

Ates, A., T. Kayıran, and I. Sincer, Structural Interpretation of the Marmara Region, NW Turkey from aeromagnetic, seismic and gravity data, Tectonophysics, 367, 41-99, 2003.

Bariş, Ş., J. Nakajima, A. Hasegawa, Y. Honkura, A. Ito, and B. Üçer, Three-dimensional structure of $\mathrm{Vp}$, Vs and $\mathrm{Vp} / \mathrm{Vs}$ in the upper crust of the Marmara region, NW Turkey, Earth Planets Space, 57, 1019-1038, 2005.

Barka, A. and K. Kadinsky-Cade, Strike-Slip fault geometry in Turkey and its influence on earthquake activity, Tectonics, 7, 663-684, 1998.

Bilim, F. and A. Ates, A computer program to estimate the source body magnetization direction from magnetic and gravity anomalies, Computers Geosci., 25, 231-240, 1999.
Bilim, F. and A. Ates, An enhanced method for estimation of body magnetization direction from pseudo-gravity and gravity data, Computers Geosci., 30, 161-171, 2004.

Bilim, F. and A. Ates, Identifying block rotations from remanent magnetization effect: Example from northern Central Turkey, Earth Planets Space, 59, 33-38, 2007.

Demirbag, E., C. Rangin, X. Le Pichon, and A. M. C. Sengor, Investigation of the tectonics of the Main Marmara Fault by means of deep towed seismic data, Tectonophysics, 361, 1-19, 2003.

Fedi, M., G. Florio, and A. Rapolla, The role of remanent magnetization in the Southern Italian crust from aeromagnetic anomalies, Terra Nova, 2, 629-637, 1991.

Fedi, M., G. Florio, and A. Rapolla, The pattern of crustal block rotations in the Italian region deduced from aeromagnetic anomalies, in Palaeomagnetism and tectonics of the Mediterranean region, edited by A. Morris and D. H. Tarling, pp. 147-152, J. Geol. Soc. (Lond.) Spec. Publ., 105, 1996.

Imren, C., X. Le Pichon, C. Rangin, E. Demirbag, B. Ecevitoglu, and N. Gorur, The North Anatolian Fault within the Sea of Marmara: a new evaluation based on multichannel seismic and multibeam data, Earth Planet. Sci. Lett., 186, 143-158, 2001.

Ludwig, J. W., J. E. Nafe, and C. L. Drake, Seismic Refraction, in The Sea 4, edited by A. E. Maxwell, pp. 53-84, John Wiley, New York, 1970.

McClusky, S., S. Balassanian, A. Barka, C. Demir, S. Ergintav, I. Georgiev, O. Gurkan, M. Hamburger, K. Hurst, H. Kahle, K. Kastens, G. Kekelidze, R. King, V. Kotzev, O. Lenk, S. Mahmoud, A. Mishin, M. Nadariya, A. Ouzounis, D. Paradissis, Y. Peter, M. Prilepin, R. Reilinger, I. Sanli, H. Seeger, A. Tealeb, M. N. Toksoz, and G. Veis, Global positioning system constraints on plate kinematics and dynamics in the eastern Mediterranean and Caucasus, J. Geophys. Res., 105, 5695-5719, 2000.

Meijer, P. T. and M. J. R. Wortel, Present-day dynamics of the Aegean region: a model analysis of the horizontal pattern of stress and deformation, Tectonics, 16, 879-895, 1997.

Meyer, P. L., Introductory probability and statistical applications, Wesley Publishing Co., Massachusetts, Addison, 1965.

Michel, G. W., M. Waldhör, J. Neugebauer, and E. Appel, Sequential rotation of stretching axes, and block rotations: a structural and paleomagnetic study along the North Anatolian Fault, Tectonophysics, 243, 97-118, 1995.

Muller, J. R. and A. Aydin, Rupture progression along discontinuous oblique fault sets: implications for the Karadere rupture segment of the 1999 Izmit earthquake, and future rupture in the Sea of Marmara, Tectonophysics, 391, 283-302, 2004.

Öncel, A. O. and T. Wilson, Evaluation of earthquake potential along the North Anatolian Fault Zone in the Marmara Sea using comparisons of GPS strain and seismotectonic parameters, Tectonophysics, 418, 205218, 2006.

Saribudak, M., M. Sanver, A. M. C. Sengor, and N. Gorur, Paleomagnetic evidence for substantial rotation of the Almacik flake within the North Anatolian Fault Zone, NW Turkey, Geophys. J. Int., 102, 563-568, 1990.

Sato, T., J. Kasahara, T. Taymaz, M. Ito, A. Kamimura, T. Hayakawa, and O. Tan, A study of microearthquake seismicity and focal mechanisms within the Sea of Marmara (NW Turkey) using ocean bottom seismometers (OBSs), Tectonophysics, 391, 303-314, 2004.

Sengor, A. M. C., The North Anatolian Transform Fault: Its age, offset and tectonic significance, J. Geol. Soc. (Lond.), 136, 269-282, 1979.

Storetvedt, K. M., Global wrench tectonics, Fagbokforlaget, Norway, 2003.

Roest, W. R. and M. Pilkington, Identifying remanent magnetization effects in magnetic data, Geophysics, 58, 653-659, 1993.

Tuncer, M. K., N. Oshiman, S. Baris, Z. Kamaci, M. A. Kaya, A. M. Isikara, and Y. Honkura, Further evidence for anomalous magnetic structure along the active fault in western Turkey, J. Geomag. Geoelectr., 43, 937-950, 1991.

A. Ates (e-mail: ates@eng.ankara.edu.tr), F. Bilim, A. Buyuksarac, and Ö. Bektas 